\title{
Regional Impacts of Long-term Climate Change on Rice Production and Agricultural Income: Evidence from Computable General Equilibrium Analysis
}

\author{
Yoji KUNIMITSU* \\ Rural Development Planning Division, National Institute for Rural Engineering of NARO (Tsukuba, \\ Ibaraki 305-8609, Japan)
}

\begin{abstract}
Future climate change will affect rice production, but whether these changes will be beneficial or detrimental is unclear. The present study evaluates the effect of climate change on Japanese rice production, rice price, agricultural income, and regional economies by using a recursive-dynamic regional computable general equilibrium (CGE) model, which is associated with crop-growth and crop-quality models. Simulation results demonstrate that future climate change will increase overall Japanese rice production nationwide, but that the price of rice will decrease. As a result, agricultural income will decrease, despite increased production in northern and eastern Japan, such as Hokkaido, Tohoku, and Kanto (including Niigata prefecture). Climate change will not benefit rice farmers in these regions. However, the western region will benefit, despite the decrease in production, and the consumer surplus in most regions will increase. This happens because rice demand is inelastic and an increase in production results in a serious decline in price, which more than offsets the effects of climate change on production. As such, the impacts of climate change are complicated and differ by region, so a CGE model can provide useful information to consider policy countermeasures.
\end{abstract}

Discipline: Agricultural economics

Additional key words: crop-growth model, crop-quality model, recursive-dynamic regional CGE model, total factor productivity (TFP)

\section{Introduction}

Agriculture is highly dependent on climate conditions, such as temperature, solar radiation, and precipitation. Future climate change will affect agricultural production and may make food supplies vulnerable. Stern (2006) predicted that agriculture in countries at higher latitudes would likely benefit from a moderate level of warming $\left(2-3^{\circ} \mathrm{C}\right)$, but that even minimal climate change in tropical regions would cause yields to decline. Japan is located at relatively high latitude, so it is possible that Japanese rice production may benefit from future climate change. However, an increased yield does not necessarily mean an economic benefit. To measure the economic effects of climate change, we need to evaluate changes in quantity and price while considering market conditions. In this sense, a comprehensive evaluation for impacts of climate change on agriculture is important for making policy decisions and from an academic interest perspective.

Changes in crop yields can be measured by field exper- iments and by using objective results of the crop-growth model based on biology. However, evaluating changes in the quantity and price of agricultural products requires economic models. Partial equilibrium models can measure such changes, but these models assume that agricultural markets do not affect the rest of the economy (i.e. they are treated as exogenous), so these models cannot fully treat the feedback effect from other goods and service markets caused by the resource restriction. Regional economies have different resource restrictions and industrial structures, so we need to consider these circumstances. A computable general equilibrium (CGE) model can depict inter-market relations and trade flows for the economy as a whole, including the circular flow of income and expenditure under resource limitation. Hence, it is better suited to analyzing global effects on agricultural markets, as happens with climate change (Palatnik \& Roson 2011). Many previous studies used CGE models to analyze the effects of climate change in Europe, the USA, and developing countries, as shown in the next section. However, few CGE frameworks have evaluated the impact of climate change on the Japanese 
rice sector.

The present study uses a CGE model to comprehensively evaluate the influence of future climate change on Japan's rice sector and regional economies. Its features are as follows: (i) the recursive-dynamic regional CGE model is used to capture regional differences in climate change; (ii) direct effects of climate conditions on rice productivity are estimated using crop-growth and crop-quality models, in addition to the global climate model (GCM), Model for Interdisciplinary Research on Climate (MIROC); (iii) farmland is introduced into the model to consider restrictions on natural resources; and (iv) the rice sector is separated from the agricultural sector, which is usually one aggregated sector in the Japanese inter-regional input-output table, to enable us to specifically study the effects on the rice sector.

Section 2 of the paper outlines previous studies that have examined the economic effects of climate change on agriculture. Section 3 explains the structure of the CGE model, data, and simulation methods used to measure the influences of climate change. Section 4 presents the simulation results. Finally, Section 5 concludes the paper, and discusses possible policy implications resulting from the analysis.

\section{Literature review and scientific question}

Furuya and Koyama (2005) analyzed the influences of climate change using the global econometric model, and estimated rice yield function by considering temperature and precipitation during the rice maturation period. Their results showed that a rise in future temperatures, as a result of global warming, would increase rice production in most Asian countries, including Japan. Their model assumed a linear influence of climate factors on production levels, but the biology-based crop-growth model showed that climate factors affected rice production in a non-linear way (Yokozawa 2009, Iizumi 2009). In other words, the effects of climate condition change from positive to negative at a threshold value, depending on plant growth. Taking such non-linear effects into account is important and useful for long-term predictions.

Kunimitsu et al. (2013) estimated the regression functions of total factor productivity (TFP) for Japanese rice production, including several causative factors such as socio-economic factors and climate conditions. In their model, the potential impact of climate factors is shown by the elasticity values of rice total factor productivity. Their results showed that (i) the potential impact of temperature and solar radiation via crop yield was high next to the economies of scale represented by farm management scale per farm organization, and that (ii) both climate and socio-economic factors increased regional gaps in rice TFP over time. Considering these features, we attempt to show how future climate change would influence Japanese rice production and price by analyzing the rice market.

A CGE model can depict market adjustment and is used to analyze agricultural production and trade liberalization by running policy simulations. Saito (2002) analyzed the effects of a farmland consolidation project on agricultural production, while Kunimitsu (2009) measured the economic effects of irrigation and drainage facilities on Japanese agriculture. CGE models used in these studies were the static one. Bann (2007) and Masui (2005) used dynamic CGE models, but did not consider precise agricultural sectors. To evaluate long-term climate change, we need to install the dynamic feature and precise production structure of agriculture in the CGE model.

Concerning climate change, Lee (2009) quantitatively analyzed climate impacts on global food prices and quantities by using a multi-sector CGE model. Similar to Stern (2006), his analysis showed that climate change benefited the crop yield of developed countries. Calzadilla et al. (2011) also used a CGE model to analyze impacts of drought on agriculture. Their results showed that the effects on welfare were mostly positive for water-stressed regions, but for non-water scarce regions, the results were more mixed and mostly negative. In most previous analyses, the global economy was classified into a few regions, and Japan was merged with OECD countries such as the USA, Western Europe, and Australia. These broad classifications make it very difficult to determine how the changes impact Japanese agriculture. Hence, a detailed multi-regional CGE model is needed to accurately and effectively analyze rice production in Japan.

As shown in the above studies, CGE models have great potential as a way of evaluating long-term impacts by considering price and quantity in the market. Since previous CGE analyses have rarely been applied to the issue of future climate change, it is interesting to apply the CGE model and evaluate whether future climate change will benefit or hinder Japanese rice production.

\section{Method}

\section{Structure of the recursive-dynamic regional CGE model}

The model used here is the recursive-dynamic CGE model with multiple regions and a structure based on the work of Bann (2007), which uses GAMS (GAMS Development Corporation) and MPSGE (a modeling tool using the mixed complementary problem), as developed by Rutherford (1999). The GAMS code of the model is shown in the APPENDIX. The major modifications are as follows:

The cost functions derived from the production functions are defined as nested-type CES (constant elasticity of substitution) forms. Figure 1 shows the structure of the cost 


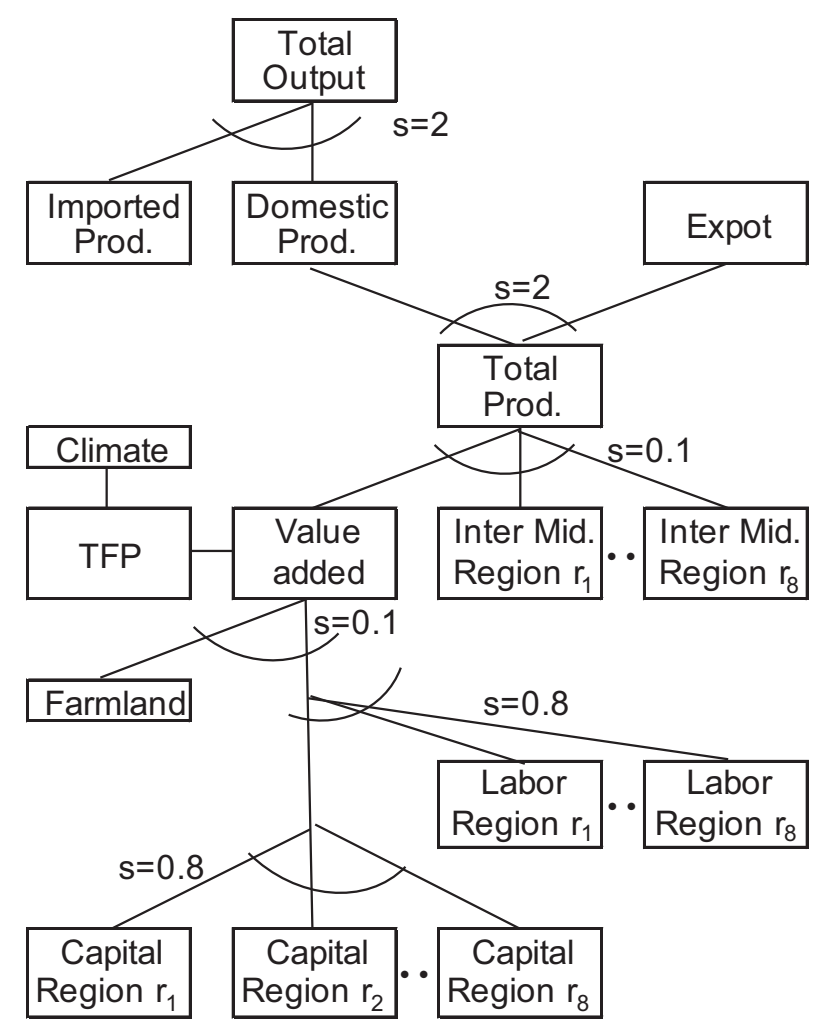

Fig. 1. Production (cost) structure

(Note) $s$ shows the elasticity value for each nest.

function. The parameter $(s)$ represents substitution elasticities, and the values are set to equivalent to those used by Bann (2007). The substitution elasticity of farmland to other input factors, which was not used in Bann (2007), is assumed to be 0.1 for agriculture. Empirical evidence on Japanese rice production from several studies showed that the substitutability of farmland for other input factors was low, but that between capital and labor was high (Egaitsu 1985). Based on these findings, we assumed that farmland is a semi-fixed input for agricultural production and not really substitutable for other factors.

TFP in the cost functions refer to the total factor productivity. With respect to climate change, TFP varies per year, and this factor is defined in previous studies as follows (Kunimitsu et al. 2013):

$$
\operatorname{TFP}_{r, t}=\beta_{0} \cdot \mathrm{MA}_{r, t}^{\beta_{1}} \cdot \mathrm{KK}_{t}^{\beta_{2}} \cdot \mathrm{CHI}_{r, t}^{\beta_{3}} \cdot \mathrm{CQI}_{r, t}^{{ }^{D R_{r}} \cdot \beta_{4}} \cdot \mathrm{CFI}_{r, t}^{\beta_{5}}
$$

Here, $T F P_{r, t}$ is the total factor productivity in year $t$ and region $r, M A$ is the management area per farmer, representing economies of scale, and $K K$ represents knowledge capital stocks accumulated through investments in research and development (R\&D). CHI, CQI, and CFI are the crop-yield index, crop-quality index, and flood index, respectively. The $\beta$ 's represent the coefficients estimated from panel data regression analysis, with $\beta_{0}=-2.7014, \beta_{1}=0.3285, \beta_{2}=$

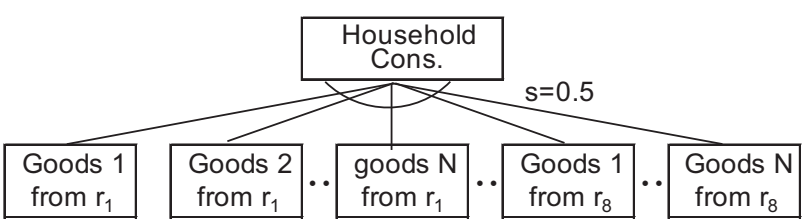

Fig. 2. Consumption structure based on the utility function

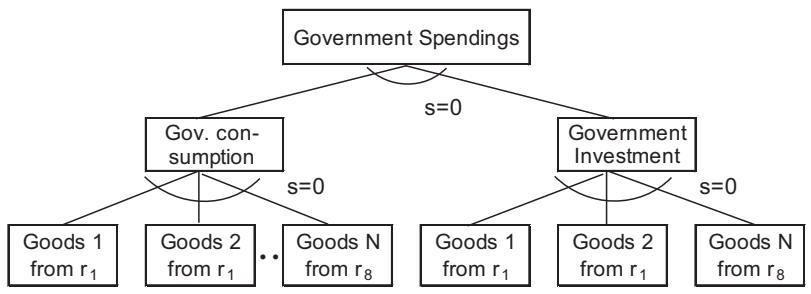

Fig. 3. Government spending structure

$0.0590, \beta_{3}=0.1824, \beta_{4}=0.0863$, and $\beta_{5}=-0.0277 . D R$ is a dummy variable, taking the value 1 for Hokkaido, and 0 otherwise. As explained in Kunimitsu et al. (2013), CHI and $C Q I$ are also defined by crop-growth and crop-quality models using climate conditions. CFI is calculated based on maximum precipitation during August and September. Namely:

$$
\begin{aligned}
& C H I_{r, t}=f\left(S R_{r, t, d a y}, \operatorname{Tmin}_{r, t, d a y}, \operatorname{Tmax}_{r, t, d a y}, C O 2_{r, t, d a y}\right) \\
& C Q I_{r, t}=f\left(S R 8_{r, t}, \operatorname{Tmin} 8_{r, t}\right) \\
& C F I_{r, t}=\max \left(\operatorname{Rain}_{r} 89_{r, t, d a y}\right)
\end{aligned}
$$

Here, $S R_{\text {day }}$ and $S R 8$ respectively denote daily solar radiation and average solar radiation in August. Tmin day, Tmax $\operatorname{Tay}_{\text {day }}$ and Tmin 8 are respectively daily minimum temperature, daily maximum temperature and average daily minimum temperature during August. Rain89 is the daily precipitation during August and September which are the typhoon season in Japan.

The prices of regional products are assumed to differ because each regional product is differentiated in the market. For example, rice produced in a certain region is sold in the market at a different price from that produced elsewhere, even though both products are classified in the same product name. Assuming these features, consumption is defined by the CES function with a substitution elasticity of 0.5 (see Fig. 2). The elasticity values of substitution in the consumption, import, and export functions are equivalent to those used by Bann (2007), which were based on the GTAP database. The government consumption and government investment (Fig. 3) are a Leontief type fixed share function. 
Household income $(H A)$ in each sector and region is defined as:

$$
\begin{aligned}
& H A_{i, r}=\left(P_{i, r} \cdot X_{i, r}-\sum_{j} P_{i, j, r} \cdot I O_{i, j, r}-\right. \\
& \left.\left(\text { Tax }_{i, r}-\text { Subsidies }_{i, r}\right)\right] / P C P_{r} \\
& =\left(P L_{r} \cdot Q L_{i, r}+P F_{r} \cdot Q L A N D_{i, r}+P K_{i, r} \cdot Q K_{i, r}\right) / P C P_{r}
\end{aligned}
$$

where $P, P L, P F, P K$ and $P C P$ respectively denote the domestic prices of goods, wages, farmland rents, annual capital service price and consumer price index. X, IO, Tax and Subsidies are respectively total production, intermediate inputs, tax and subsidies in each sector and region. $Q L$, $Q L A N D$ and $Q K$ respectively denote labor, farmland and capital stocks demanded in each sector. Total supplies of $Q L$ and $Q L A N D$ are exogenously determined, even though these factors move among production sectors within the region according to changes in the factor price.

To form the recursive-dynamic path, the capital stock equation is defined by annual investment $(I)$ and disposable rate $(\delta=0.04)$, as follows:

$$
K_{r, t}=(1-\delta) K_{r, t-1}+I_{r, t}
$$

Here, $K$ shows capital supply and is defined for every year from $I$, which is endogenously defined.

\section{Data and simulation method}

To calibrate the parameters of the model, the social accounting matrix (SAM) was estimated based on Japan's 2005 inter-regional input-output table. To analyze rice production more precisely, the rice sector was separated from the sector of aggregated agriculture, forestry, and fishery in the IO table, based on regional tables ( $404 \times 350$ sectors). Subsequently, the sectors were reassembled into 14 sectors: rice; other agriculture, forestry and fishery; mining and fuel; food processing; chemical products; general machinery; electrical equipment and machinery; other manufacturing; construction; electricity and gas; water; wholesale and retail sales; financial services; and other services. Regions were also reassembled into eight areas: Hokkaido; Tohoku; Kanto including Niigata prefecture; Chubu; Kinki; Chugoku; Shikoku; and Kyushu including Okinawa.

The factor input value of farmland, not shown in the Japanese I/O table, was estimated using farmland cultivation areas (Farmland statistics, Ministry of Agriculture, Forestry, and Fishery, and every year) and multiplying the areas by farmland rents. The factor input value of farmland was subtracted from the operation surplus in the original IO table. The value of capital input was subsequently composed of the remaining operational surplus and the depreciation value of capital.
To show the macroeconomic impacts of climate change, we simulate future economic circumstances with and without climate change, i.e. the base case (CASE 0) and climate change case (CASE 1), as follows:

CASE 0: This case represents business as usual, and is used as the baseline. In this case, farmland supply and labor supply in each region were fixed at the present levels shown in the SAM data. The technological growth rate of the Japanese economy was assumed to be 0 to show only the effects of climate change. The TFP of rice production was also set to 1 , showing no progress in technology and no change in climate conditions. Other exogenous variables, i.e. government savings, foreign savings, regional transfer, were also fixed at the present levels.

CASE 1: This case represents future climate change that only affects rice production. Exogenous variables other than rice TFP were set to the same values as in CASE 0 . The future rice $T F P$ levels were calculated by using Eq. (1), as shown in Figure 4. These TFPs include the influence of both socio-economic factors $(M A$ and $K K)$ and climate factors (CHI, CQI, and CFI). To estimate the pure effect of climate factors, the ratio of chronological TFP change, i.e. ${ }_{t f p_{r, t}}=T_{F P} P_{r, t} / T_{F P}^{\prime}{ }_{r, t 0}^{\prime}=\left(C H I_{r, t} / C H I_{r, t 0}\right)^{\beta_{3}} \cdot\left(C Q I_{r, t} / C Q I_{r, t 0}\right)^{D R_{r} \beta_{4}}$. $\left(C F I_{r, t} / C F I_{r, t 0}\right)^{\beta_{5}}$, is set for simulation (see Figure 5), where $T F P_{r, t}$ is calculated by Eq. (1) with all variables and $T F P^{\prime}{ }_{r, t 0}$ is calculated by socio-economic factors and initial climate conditions with the same estimated coefficients as Eq. (1). Changes in annual climate factors were predicted by using the crop-growth model (Eq. (2)), crop-quality model (Eq. (3)), and maximum precipitation (Eq. (4)), along with the projection results of MIROC, high-resolution version 3.0 (K-1 Model Developers, 2004) (Figure 6). The greenhouse gas emission scenario was A1B which shows balanced growth alongside rapid economic growth, low population growth, and the rapid introduction of more efficient technology in the Special Report on Emission Scenario (SRES) (Nakicenovic \& Swart 2000).

The effects of climate change are measured by the ratio or difference between both cases. Assumptions on future socio-economic factors in both cases cancel each other out and have minimal influence on our results; even though our assumptions are too simple to duplicate future economic growth.

\section{Results}

To ensure stable simulation results, a sensitivity analysis was conducted by changing the substitution elasticities of demand and inter-regional material demand as intermediate inputs. The degree of impact changed, but the directions of the changes remained the same for all variables. The results presented below are reasonably stable and common, provided the economic structure remains unchanged. 
(a) Hokkaido and Tohoku

1.15
1.10
1.05
1.00
0.95

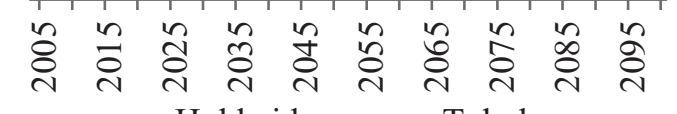

(c) Kinki and Chugoku

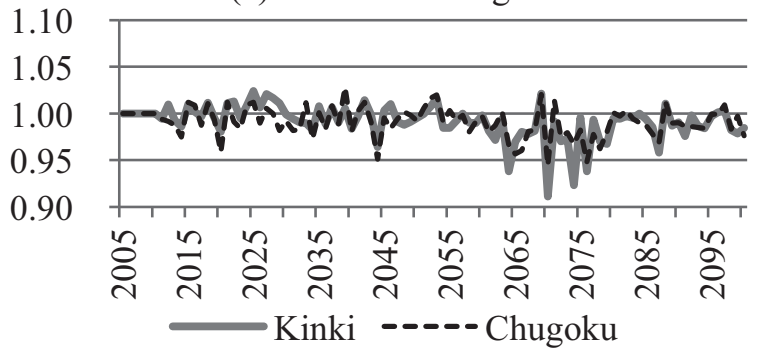

(b) Kanto and Chubu

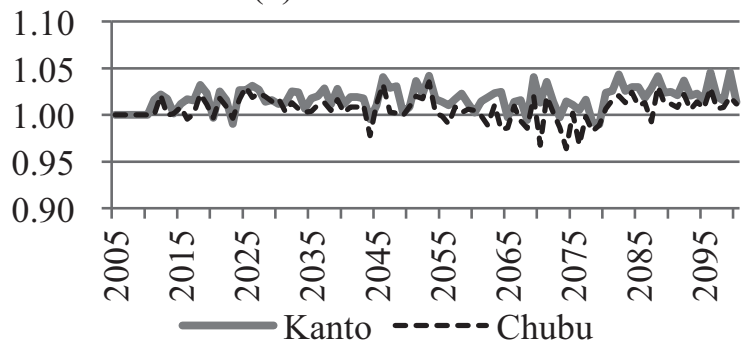

(d) Shikoku and Kyushyu

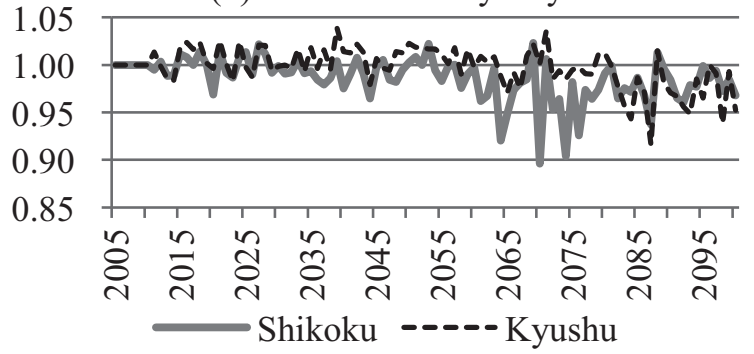

Fig. 4. Chronological level of rice TFPs caused by changes in socio-economic and climate factors

(Source) Kunimitsu et al. (2013)

(Note) The prefectures included in Kanto and Chubu in this study are different from Kunimitsu et al., so regional TFP values for simulation analysis were recalculated by considering the production share rate of prefectural rice production. In other words, $T F P_{\text {kanto }}=0.8 \times T F P_{\text {Kanto }}^{*}+0.2 \times T F P_{\text {Hokuriku }}^{*}$, and $T F P_{\text {Chubu }}=0.5 \times T F P_{\text {Hokuriku }}^{*}+0.5 \times T F P_{\text {Tokai }}^{*}$, where $T F P^{*}$ is the TFP value in Kunimitsu et al.

1.15

1.10

1.05

1.00

0.95

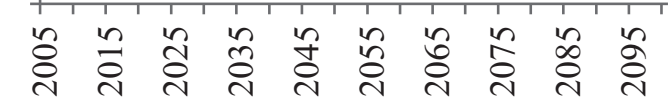

Hokkaido ------ Tohoku

(c) Kinki and Chugoku

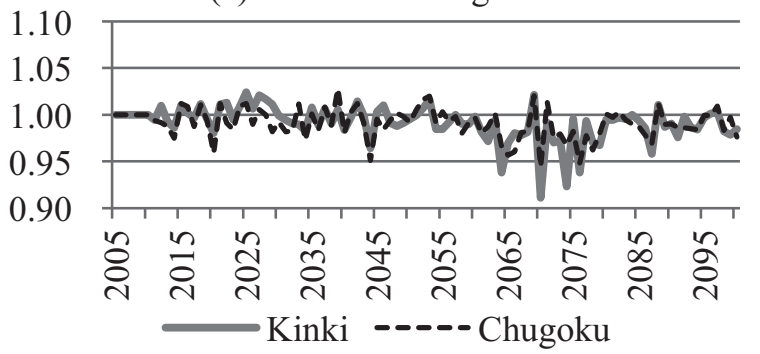

(b) Kanto and Chubu

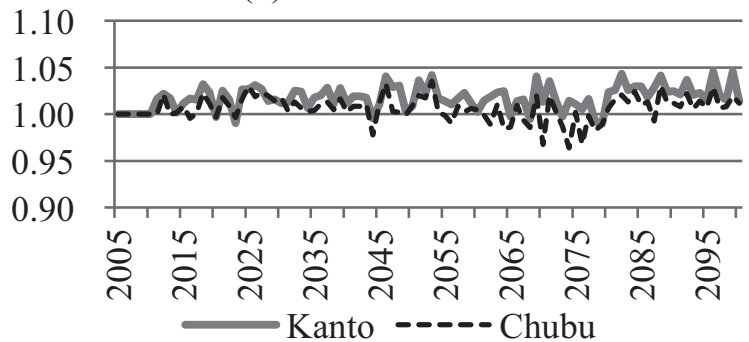

(d) Shikoku and Kyushyu

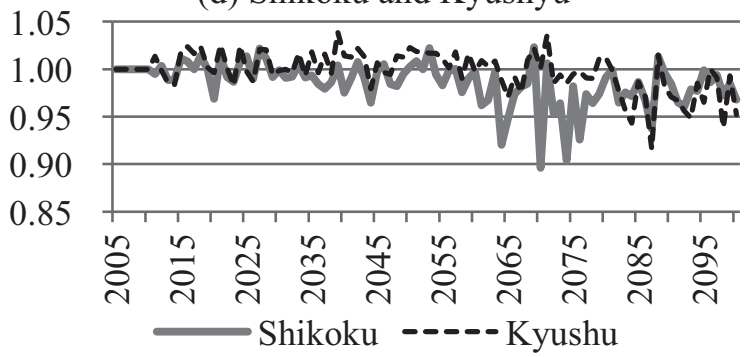

Fig. 5. Relative TFP changes $\left(t f p_{r, t}\right)$ in rice production sector for simulation

(Note) To simulate the pure effect of climate factors, TFP in each region was set as $t f p_{r, t}=T F P_{r, t} / T F P_{r, t 0}^{\prime}=\left(C H I_{r, t}\right)$ $\left.C H I_{r, t 0}\right)^{\beta_{3}} \cdot\left(C Q I_{r, t} / C Q I_{r, t 0}\right)^{D R_{r} \beta_{4}} \cdot\left(C F I_{r, t} / C F I_{r, t 0}\right)^{\beta_{5}}$, where $T F P_{r, t}$ is calculated by Eq. (1) with all variables and $T F P_{r, t 0}$ is calculated by socio-economic factors and initial climate conditions with the same estimated coefficients as Eq. (1). 

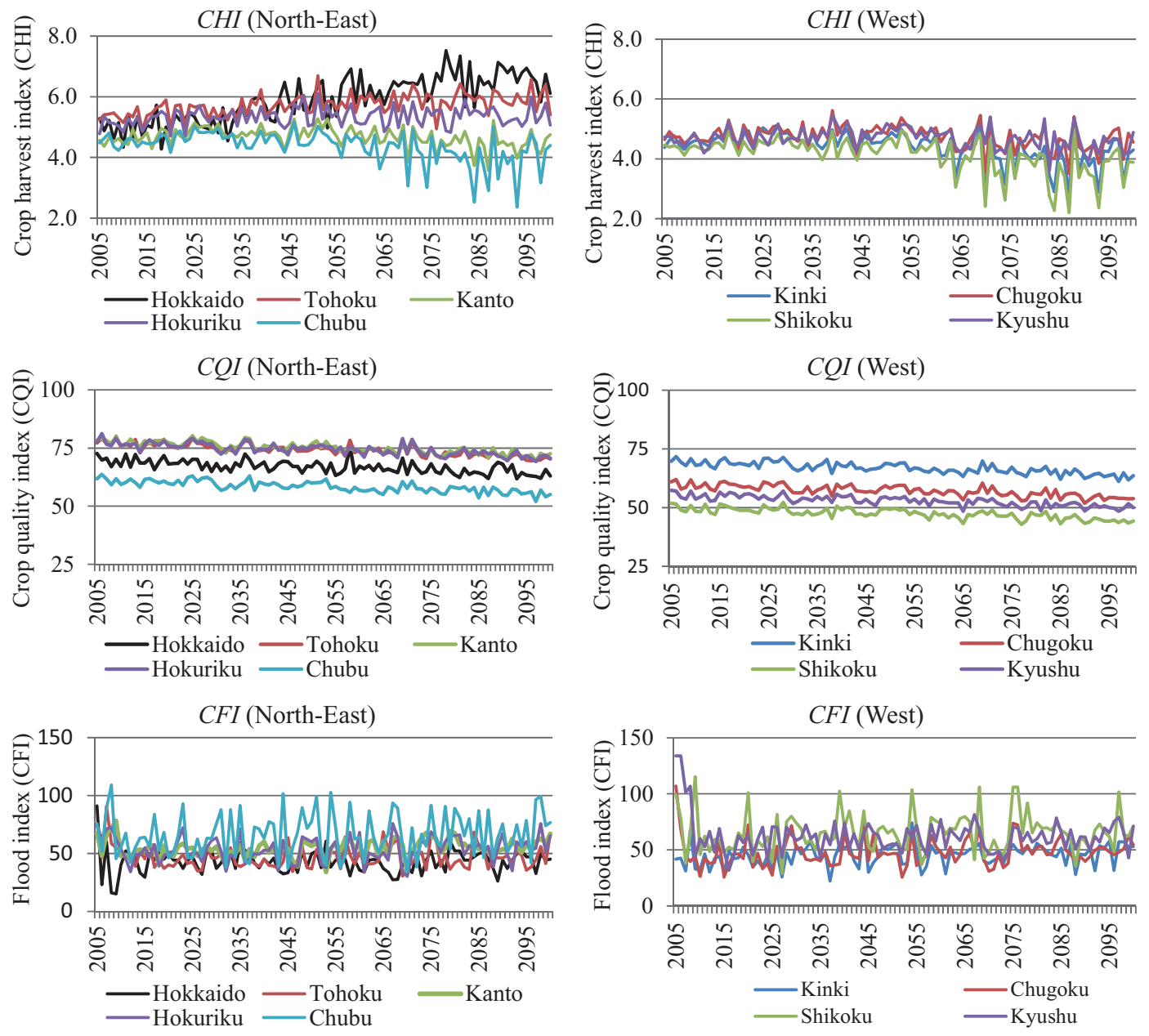

Fig. 6. Chronological level of crop yield index, $C H I$, crop quality index, $C Q I$, and flood index, $C F I$

\section{Rice production and price}

Figure 7 shows chronological changes in rice production values estimated with TFP changes. Although the exogenous variables were set as the status quo, rice production in CASE 0 increased as a result of an increase in capital stocks, which were endogenously accumulated by annual investment. The difference between CASES 1 and 0 shows only the effects of changes in climate factors. In Tohoku and Kanto, rice production was relatively large, so the scale of vertical axis in these regions was double that of the other regions, but the growth rate of rice production was almost equivalent to other regions.

In accordance with the TFP changes shown in Figure 6 , the line of Case 1 exceeded that of Case 0 in northern and eastern regions, such as Hokkaido, Tohoku, and Kanto (including Niigata prefecture). This shows that climate change caused an increase in rice production there. However, rice production declined in western regions, such as Kinki, Chugoku, Shikoku, and Kyushu.

In all regions, annual production fluctuated under climate change. Even in northern and eastern regions, produc- tion levels fell below the CASE 0 level in some years, except Hokkaido. Rice production in Hokkaido benefited in all years, even under bad climate conditions. The western regions experienced worse production than CASE 0 in many years, but the difference between CASES 1 and 0 fluctuated over time and this degree of fluctuation increased after 2050. Until then, climate conditions tended to increase the crop yield, but decrease crop quality. However, from the 2050s onwards, when temperatures frequently exceeded the threshold level, climate conditions decreased both crop yield and quality, showing agglomeration effects. Tohoku, Kanto, and Kyushu seemed to experience wider fluctuations in production, but variation coefficients there were almost equivalent to elsewhere because their rice production was relatively large. In the western regions, the decreases in crop yield and quality intensified during the latter simulation period, largely because of negative agglomeration effects of temperature on rice TFP via rice yield and quality.

Table 1 shows the average of annual production values from 2005 to 2100 . The northern and eastern regions show positive production values and would be able to increase 

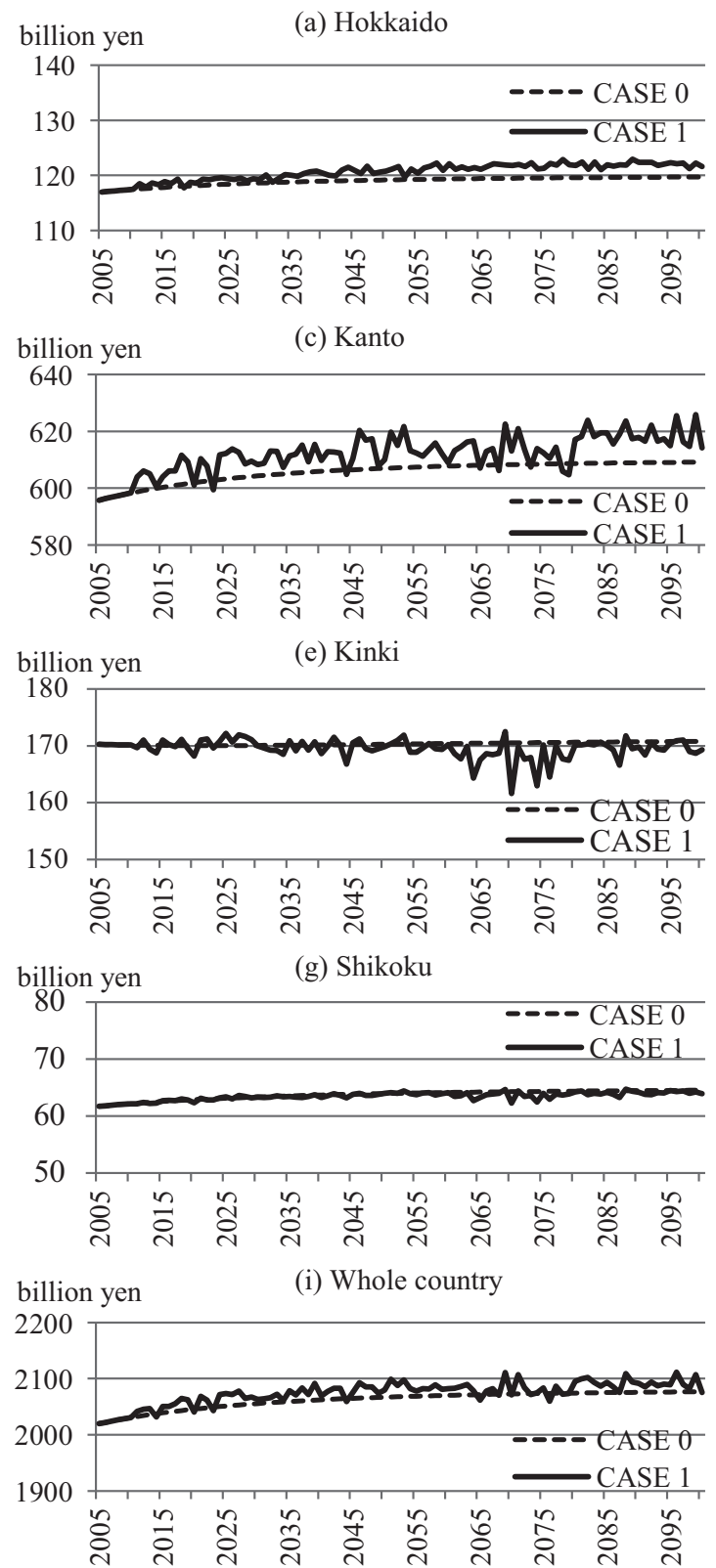
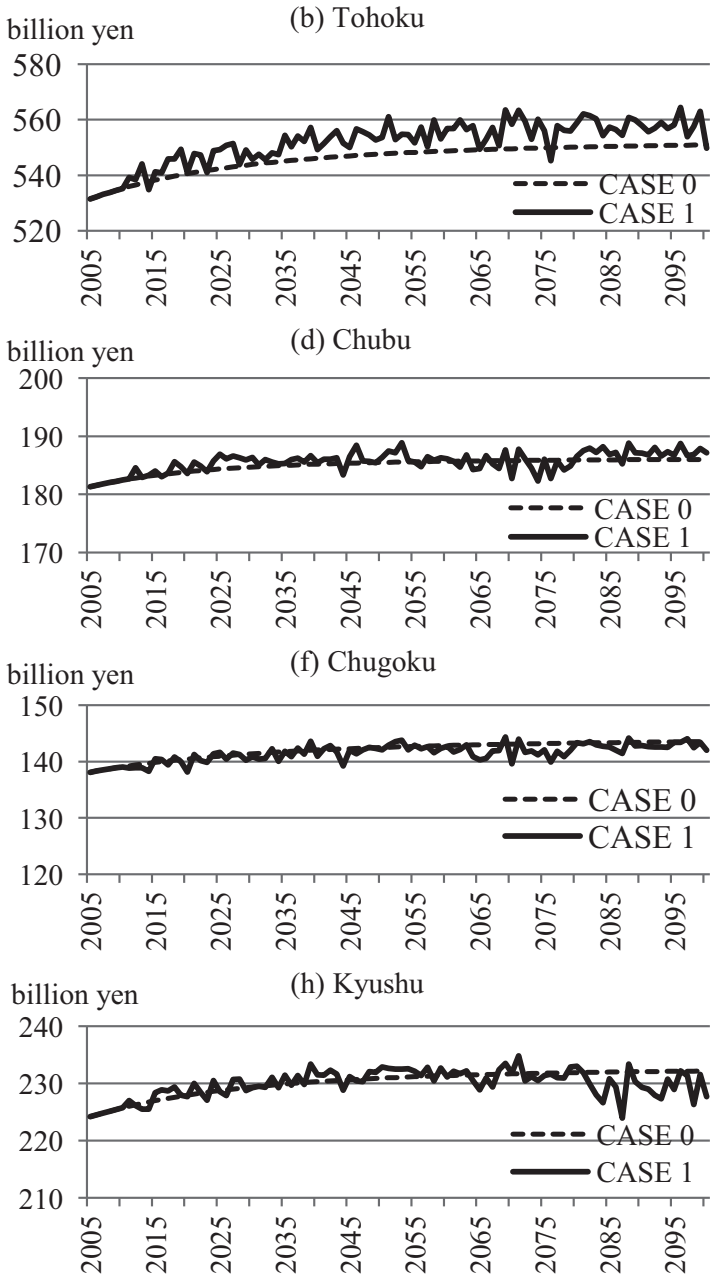

Fig. 7. Quantities of paddy rice production

their total production beyond that of CASE 0 . The increase in production accelerated in these regions in the latter simulation period. Conversely, climate change adversely affected the western regions, and this was exacerbated in the latter part of the simulation period due to the above-mentioned agglomeration effects of temperature. These results clearly show that the effects of climate change on rice production differ according to location.

Figure 8 shows price changes in the rice sector resulting from climate change alone. In contrast to production quantity, the price of rice decreased in northern and eastern regions, but increased in the west. Rice consumption increased slightly and regional rice products were differenti- ated in the market, so the price dropped in those regions where production increased, but rose where it declined. This is because the share rate of rice consumption is low in actual Japanese SAM data, which renders rice demand inelastic. Consequently, an imbalance in supply and demand is reflected in a sharp change in price. Such circumstances are consistent with the actual market, where rice produced in different regions has different prices.

\section{Prices of input factors and agricultural income}

Table 2 shows factor price changes in the rice sector. The directions of the changes in factor prices were equivalent to those of the rice prices in all regions. In other words, 
Table 1. Annual average of rice production values (in real terms) from 2005 to 2100 by regions

Billion yen/year

\begin{tabular}{lrrrrrr}
\hline \hline \multirow{2}{*}{ Regions } & \multicolumn{3}{c}{$2005-2050$} & & $2051-2100$ \\
\cline { 2 - 6 } & CASE 0 & CASE 1 & Diff. & CASE 0 & CASE 1 & Diff. \\
\hline Hokkaido & 118 & 119 & 1.0 & 120 & 122 & 2.2 \\
Tohoku & 542 & 546 & 4.5 & 550 & 557 & 7.1 \\
Kanto & 603 & 608 & 5.1 & 608 & 616 & 7.2 \\
Chubu & 184 & 185 & 0.7 & 186 & 186 & 0.4 \\
Kinki & 170 & 170 & 0.0 & 171 & 169 & -1.5 \\
Chugoku & 141 & 141 & -0.3 & 143 & 142 & -0.8 \\
Shikoku & 63 & 63 & -0.1 & 64 & 64 & -0.4 \\
Kyushu & 229 & 229 & 0.5 & 232 & 231 & -1.0 \\
Whole & 2,050 & 2,062 & 11.3 & 2,073 & 2,086 & 13.3 \\
\hline
\end{tabular}

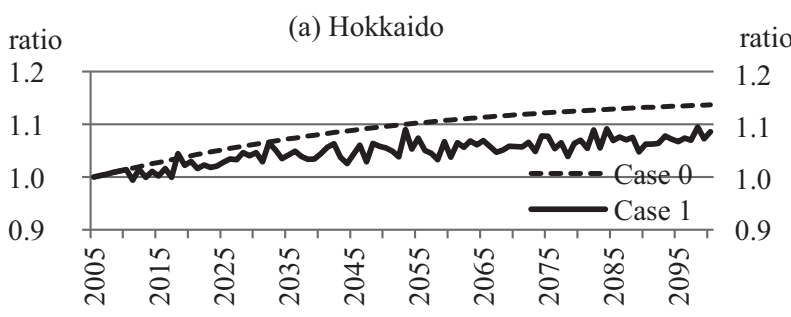

(c) Kanto
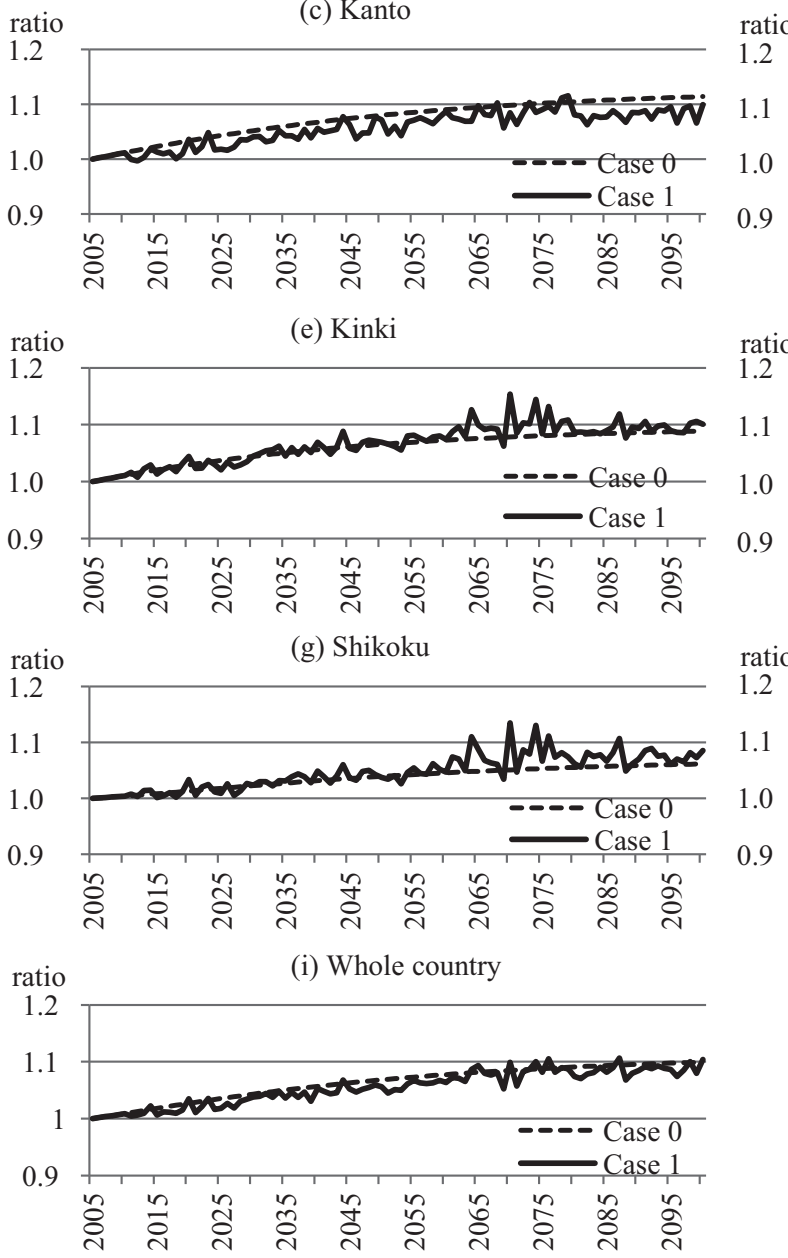
(b) Tohoku

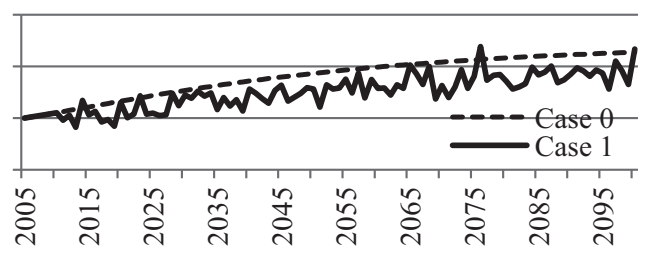

(d) Chubu

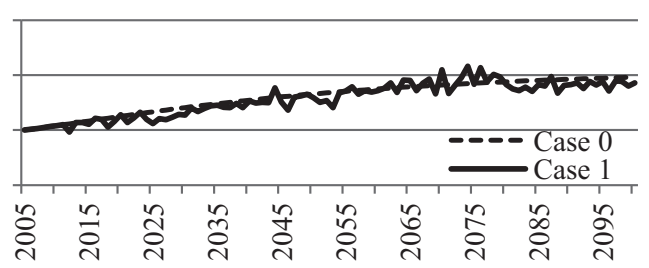

(f) Chugoku

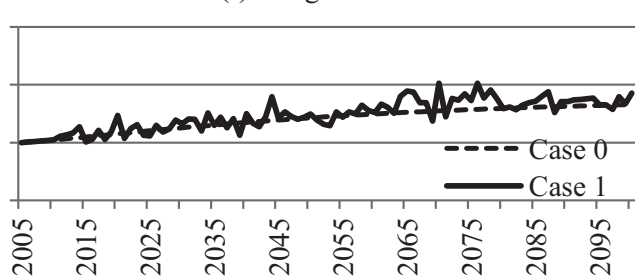

(h) Kyushu

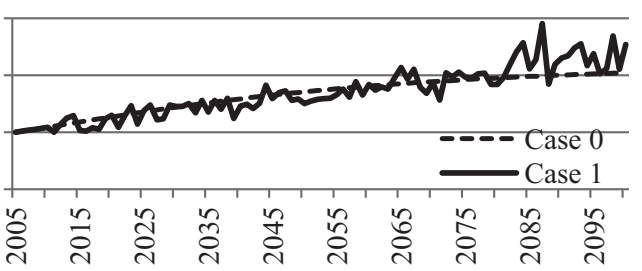

Fig. 8. Prices of paddy rice product

(Note) The unit of vertical axis is the ratio of price in each year against price in 2005. 
Table 2. Changes in factor prices by regions against initial year

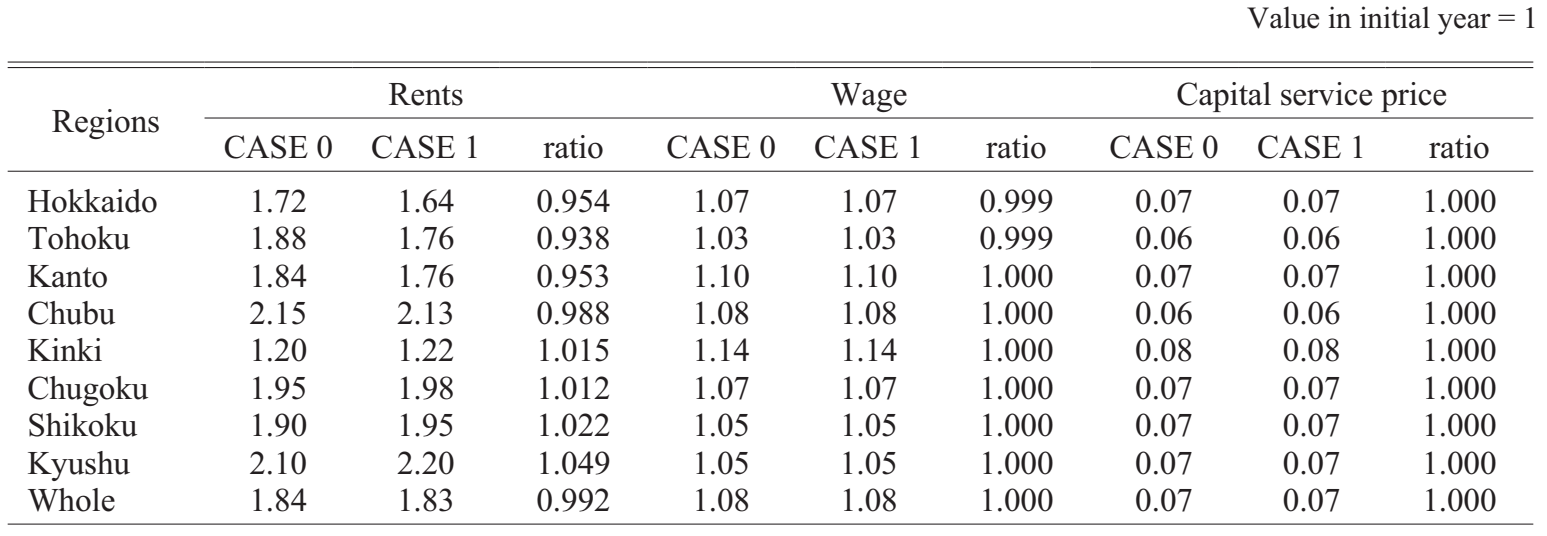

Table 3. Annual average agricultural income in rice sector

Billion yen/year

\begin{tabular}{lrrrrrr}
\hline \hline & \multicolumn{3}{c}{$2005-2050$} & \multicolumn{3}{c}{ 2051-2100 } \\
\cline { 2 - 6 } & CASE 0 & CASE 1 & Diff. & CASE 0 & CASE 1 & Diff. \\
\hline Hokkaido & 63 & 61 & -1.9 & 71 & 66 & -4.6 \\
Tohoku & 278 & 269 & -8.2 & 321 & 307 & -13.5 \\
Kanto & 312 & 307 & -4.8 & 347 & 340 & -6.7 \\
Chubu & 92 & 91 & -0.6 & 102 & 102 & -0.3 \\
Kinki & 86 & 86 & 0.1 & 89 & 90 & 1.0 \\
Chugoku & 73 & 73 & 0.4 & 79 & 80 & 0.9 \\
Shikoku & 30 & 30 & 0.1 & 33 & 33 & 0.7 \\
Kyushu & 111 & 110 & -0.7 & 126 & 128 & 1.8 \\
Whole & 1,045 & 1,029 & -15.6 & 1,167 & 1,146 & -20.7 \\
\hline
\end{tabular}

the northern and eastern regions, where the rice price decreased, experienced a decrease in factor prices, and the western regions experienced an increase in factor prices. Changes in farmland rental rates prevailed over other factors, because we assumed low substitution elasticity of farmland to other factors. In addition, farmland is immobile, and used only for agriculture, so changes in rice price and production within the region directly affect farmland rental values.

Table 3 shows average agricultural income in the rice sector (deflated by the consumer price index), as affected by rental rate, wage, and capital service price. The same tendency emerged in the agricultural income of all relating agricultural sectors, but these results were omitted here due to lack of space. Agricultural income decreased in northern and eastern regions, where rice production rose after climate change, but agricultural income in the western regions (decreased rice production) increased. This was due to changes in the price of rice, which were inverse to the changes in rice production due to inelastic demand against price change. Based on these features, an increase in rice production amid unexpected climate change triggers a decrease in agricultural income ${ }^{1}$. In other words, the degree of price changes exceeded the degree of production changes.

Agricultural income nationwide decreased as a result of climate change, and the negative impact on overall income also intensified in the latter simulation period. Overall, climate change does not benefit farmers.

\section{Gross regional production and social welfare}

Table 4 shows average gross regional production (GRP) during the simulation periods. In contrast to agricultural income, changes in GRP were positive in Kanto and Chubu. Since Kanto and Chubu have sizeable manufacturing industries, demand for manufacturing and service goods,

${ }^{1}$ Price elasticity of demand is defined as $\eta=-\frac{\Delta X}{X} \mid \frac{\Delta P}{P}$, and total revenue (Y), which is the main source of income as defined in Eq. (5), is defined as $P \cdot X$. The change rate of total revenue is $\frac{\Delta Y}{Y}=\frac{\Delta X}{X}+\frac{\Delta P}{P}=\left(1-\frac{1}{\eta}\right) \frac{\Delta X}{X}$. Therefore, if $0<\eta<1$, which shows an inelastic demand situation, the change in $X$ causes a decline in total revenue. 
Table 4. Annual average GRP from 2005 to 2100 by regions

Billion yen/year

\begin{tabular}{lrrrrrr}
\hline \hline \multirow{2}{*}{ Regions } & \multicolumn{3}{c}{$2005-2050$} & & \multicolumn{3}{c}{ 2051-2100 } \\
\cline { 2 - 6 } & \multicolumn{1}{c}{ CASE 0 } & \multicolumn{1}{c}{ CASE 1 } & \multicolumn{1}{c}{ Diff. } & \multicolumn{1}{c}{ CASE 0 } & \multicolumn{1}{c}{ CASE 1 } & \multicolumn{1}{c}{ Diff. } \\
\hline Hokkaido & 20,744 & 20,745 & 0.8 & 22,937 & 22,936 & -1.1 \\
Tohoku & 33,759 & 33,756 & -3.3 & 37,870 & 37,862 & -7.9 \\
Kanto & 210,880 & 210,900 & 20.1 & 238,516 & 238,559 & 43.3 \\
Chubu & 61,736 & 61,736 & 0.5 & 69,947 & 69,948 & 1.1 \\
Kinki & 80,497 & 80,500 & 3.0 & 88,918 & 88,921 & 3.1 \\
Chugoku & 29,909 & 29,908 & -0.6 & 33,445 & 33,443 & -1.7 \\
Shikoku & 14,950 & 14,950 & -0.1 & 16,541 & 16,541 & 0.3 \\
Kyushu & 54,992 & 54,991 & -0.6 & 61,637 & 61,635 & -2.3 \\
Whole & 507,467 & 507,487 & 19.8 & 569,811 & 569,845 & 34.9 \\
\hline
\end{tabular}

Table 5. Annual average Equivalent Valuation from 2005 to 2100 by regions

Billion yen/year

\begin{tabular}{lrrrrrr}
\hline \hline \multirow{2}{*}{ Regions } & \multicolumn{3}{c}{$2005-2050$} & & \multicolumn{3}{c}{ 2051-2100 } \\
\cline { 2 - 6 } & CASE 0 & CASE 1 & Diff. & CASE 0 & CASE 1 & Diff. \\
\hline Hokkaido & 284 & 283 & -0.6 & 629 & 624 & -4.4 \\
Tohoku & 475 & 469 & -6.6 & 1,091 & 1,080 & -11.4 \\
Kanto & 5,294 & 5,311 & 16.6 & 11,727 & 11,758 & 31.2 \\
Chubu & 1,131 & 1,132 & 1.0 & 2,521 & 2,523 & 2.1 \\
Kinki & 1,677 & 1,681 & 4.0 & 3,819 & 3,824 & 5.3 \\
Chugoku & 453 & 454 & 0.5 & 1,029 & 1,029 & 0.2 \\
Shikoku & 159 & 160 & 0.3 & 373 & 374 & 1.3 \\
Kyushu & 844 & 844 & -0.3 & 1,793 & 1,794 & 0.9 \\
Whole & 10,318 & 10,333 & 15.0 & 22,981 & 23,006 & 25.3 \\
\hline
\end{tabular}

which could increase by the shift of production factors from the rice sector after the increase in rice TFP, became concentrated there. Overall, the total GRP for the country increased after climate change. However, Chugoku and Shikoku experienced minor losses in GRP, due to the relatively weak manufacturing sector in these regions.

Table 5 shows average equivalent variation (EV) corresponding to the consumer surplus and social welfare level. $\mathrm{EV}$ in most regions increased after climate change, and even Chugoku and Shikoku, where the GRP effects were negative, experienced an increase in welfare. The difference between EV and GRP is mostly due to price effects, meaning the negative income effects overwhelmed the substitution effects caused by price change. EV in Hokkaido and Tohoku became negative, but any adverse effect was much smaller than the negative effect on income. In fact, social welfare levels of non-agricultural sectors increased in these regions, although it could not overcome agricultural income loss. Summing these regional effects, the EV change nationwide became positive, and climate change benefits Japanese consumers.

\section{Discussion and conclusion}

This study used the CGE model to comprehensively evaluate the influence of future climate change on Japan's rice sector and regional economies. We built the recursivedynamic regional CGE model associated with the cropgrowth and crop-quality model and then used it to simulate the future impacts of climate change predicted by the global climate model, MIROC. Based on our simulation results, there are several policy implications as follows:

First, future climate change increases rice production nationwide, but causes rice prices to decrease. As a result of these inverse effects, agricultural income in the rice sector decreases, despite the increase in production output. This is due to the inelastic demand for rice, which does not increase significantly even after the price falls. In northern and eastern parts of Japan, such as Hokkaido, Tohoku, and Kanto (including Niigata prefecture), rice production increased after climate change, but rice prices and agricultural income decreased. In contrast, the western regions experienced an increase in price and income, despite the decrease in production. Climate change benefits regions where the total factor productivity for rice decreases with extremely high temperatures. These effects are somewhat counterintuitive, as they show that agricultural income can- 
not be improved in areas where climate change primarily increases rice TFP. In real data, these effects may be too small to observe, because the Japanese rice sector is small when compared to other industries. Of course, such effects are also highly dependent on parameter values, such as substitution elasticities. Accordingly, it is important to use an economic model with quantified parameters by econometric methods and precise data for policymaking.

Second, the GRP and social welfare level measured by the EV change may improve after climate change in most regions, as well as on a national level in Japan. These findings correspond to other studies on higher altitude countries. However, most of these favorable regions are urbanized areas where manufacturing and service industries are already developed. Rural areas, especially those of major rice production, such as Hokkaido and Tohoku in Japan, will suffer from a loss of income, despite an expected increase in productivity. It is important to improve rice productivity by accelerating research and development activities and maintaining the farmer's per-capita income by using policy measure, such as direct payments.

Third, the main reason why agricultural income cannot be improved is the limitation in demand for rice in Japan. If there were scope for rice demand to increase further after a decrease in price, the scenario presented here could change completely. In this sense, developing demand is critical to Japanese rice production. This should include increasing domestic demand for rice, making the rice market flexible to price on both supply and demand sides, and decreasing the price. Such deregulation could boost inter-regional trade of rice in the domestic market. Furthermore, amid the currently shrinking population in Japan, it is difficult to create new domestic demand, so demand overseas is also necessary for continued domestic production. A policy to promote the export of Japanese rice is required.

There are several remaining issues in this study. First, we used the same values for most parameters as those in previous studies, due to the lack of empirical results, particularly on substitution elasticities for inter-regionally traded goods. More empirical analysis is needed. Second, this study used 2005 data, based on the most recent published I/ $\mathrm{O}$ table, so more recent data are necessary. Third, because of the computational ability, the CGE model used here has 14 sectors and 8 regions, but it is important to handle more precise sectors and regions. In addition, other possible future tasks include analyzing climate impacts on other agricultural sectors, forestry, and fishery, measuring them by considering trade liberalization, and evaluating policy instruments against future climate change.

\section{Appendix}

The CGE model used here was composed using GAMS with an MPSGE solver. The syntax of MPSGE is shown in Rutherford (1999). In equations, suffixes of $i$ and $j$ show sector classifications, while those of $p$ and $r$ show regions. The variables used in the model are explained in Table A-1. The numeraire of the price in the model is the consumer price index in the Kanto region where consumption quantities are the largest in Japan.

* MPSGE model

\begin{tabular}{|c|c|}
\hline \multicolumn{2}{|l|}{ Sontext } \\
\hline \multicolumn{2}{|l|}{ \$model:MRM_jpn } \\
\hline \multicolumn{2}{|l|}{ \$sectors: } \\
\hline $\mathrm{X}(\mathrm{i}, \mathrm{r})$ & ! Production \\
\hline XV(i,r) & ! Value added production \\
\hline $\mathrm{XA}(\mathrm{i}, \mathrm{r})$ & ! Armington aggregate \\
\hline $\mathrm{M}(\mathrm{i}, \mathrm{r}) \$ \mathrm{M} 0(\mathrm{i}, \mathrm{r})$ & ! Import \\
\hline $\mathrm{E}(\mathrm{i}, \mathrm{r}) \$ \mathrm{E} 0(\mathrm{i}, \mathrm{r})$ & ! Export \\
\hline $\mathrm{CP}(\mathrm{r})$ & ! Household consumption \\
\hline $\mathrm{CG}(\mathrm{r})$ & ! Government consumption \\
\hline $\mathrm{IG}(\mathrm{r})$ & ! Public investment \\
\hline $\mathrm{IP}(\mathrm{r})$ & ! Private investment \\
\hline \multicolumn{2}{|l|}{ \$commodities: } \\
\hline $\mathrm{PV}(\mathrm{i}, \mathrm{r})$ & ! Price of value added production \\
\hline $\mathrm{P}(\mathrm{i}, \mathrm{r})$ & ! Price of output for domestic use \\
\hline $\mathrm{PA}(\mathrm{i}, \mathrm{r})$ & ! Price of armington aggregates \\
\hline $\operatorname{PM}(i, r) \$ M 0(i, r)$ & ! Price of import goods \\
\hline PE(i,r)\$E0(i,r) & ! Price of export goods \\
\hline $\mathrm{PCP}(\mathrm{r})$ & ! Price of consumption \\
\hline PCG(r) & ! Price of government consumption \\
\hline PIG(r) & ! Price of public investment \\
\hline $\mathrm{PIP}(\mathrm{r})$ & ! Price of private investment \\
\hline $\mathrm{PL}(\mathrm{r})$ & ! Wage rate \\
\hline $\mathrm{PK}(\mathrm{r})$ & ! Capital service price \\
\hline $\mathrm{PF}(\mathrm{r})$ & ! Rental rate of farmland \\
\hline PFX & ! Foreign exchange \\
\hline \multicolumn{2}{|l|}{ \$consumers: } \\
\hline $\mathrm{HA}(\mathrm{r})$ & ! Household agent \\
\hline GOV(r) & ! Government \\
\hline \$prod:XV(j,r) & s:0.1 va1:0.8 \\
\hline $\mathrm{o}: \mathrm{PV}(\mathrm{j}, \mathrm{r})$ & $\mathrm{q}:\left(\mathrm{XV0}(\mathrm{j}, \mathrm{r})^{*} \mathrm{TFP}(\mathrm{j}, \mathrm{r})\right)$ \\
\hline $\mathrm{i}: \mathrm{PF}(\mathrm{r}) \$ \mathrm{~F} 0(\mathrm{j}, \mathrm{r})$ & $\mathrm{q}: \mathrm{F0}(\mathrm{j}, \mathrm{r}) \quad \mathrm{p}: \mathrm{PF} 0(\mathrm{r})$ \\
\hline \multirow[t]{2}{*}{$\mathrm{i}: \mathrm{PL}(\mathrm{p})$} & $\mathrm{q}: \mathrm{L} 0(\mathrm{j}, \mathrm{p}, \mathrm{r}) \quad \mathrm{p}: \mathrm{PL} 0(\mathrm{p})$ \\
\hline & a:GOV(p) t:taxl(p) val: \\
\hline \multirow[t]{2}{*}{$\mathrm{i}: \mathrm{PK}(\mathrm{p})$} & $\mathrm{q}: \mathrm{K} 0(\mathrm{j}, \mathrm{p}, \mathrm{r}) \quad \mathrm{p}: \mathrm{PK} 0(\mathrm{p})$ \\
\hline & a:GOV(p) t:taxk(p) va2: \\
\hline \multicolumn{2}{|c|}{ \$prod:X(j,r)\$E0(j,r) t:2 s:0.1 } \\
\hline $\mathrm{o}: \mathrm{P}(\mathrm{j}, \mathrm{r}) \quad \mathrm{q}: \mathrm{XD} 0(\mathrm{j}, \mathrm{r})$ & p:PX0(j,r) a:GOV(r) t:taxy(j,r) \\
\hline $\mathrm{o}: \mathrm{PE}(\mathrm{j}, \mathrm{r}) \quad \mathrm{q}: \mathrm{E} 0(\mathrm{j}, \mathrm{r})$ & p:PX0(j,r) a:GOV(r) t:taxy(j,r) \\
\hline i:PA(i,p) q:IO0(i,j,p & \\
\hline $\mathrm{i}: P V(j, r) \quad q: X V 0(j, r)$ & \\
\hline
\end{tabular}



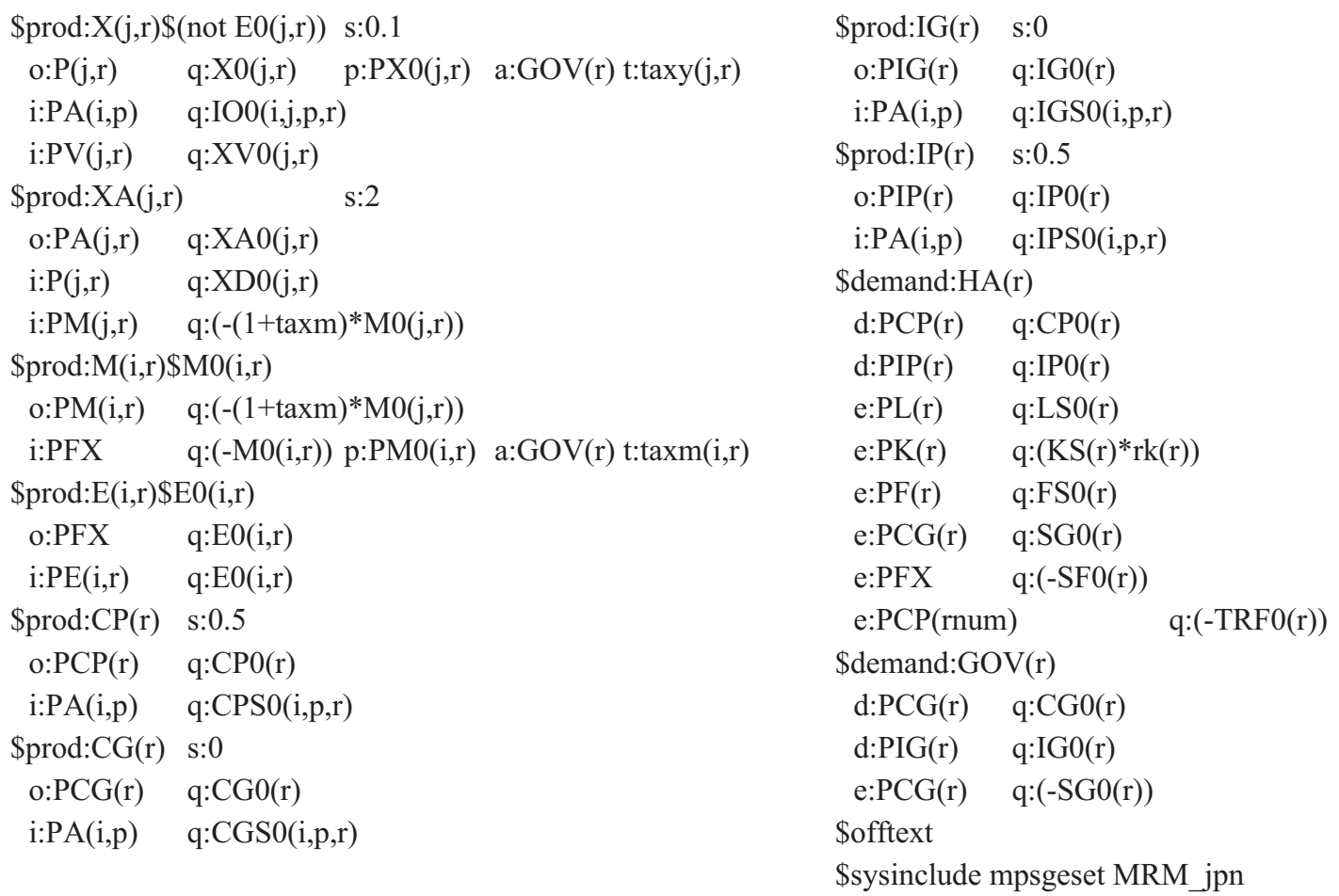

Table A-1. Variables used in the model

\begin{tabular}{|c|c|c|c|}
\hline Variables & Contents & Variables & Contents \\
\hline$X$ & production & $P F X$ & Foreign exchange \\
\hline$X V$ & value added production & $P V$ & price of value added production \\
\hline$X D$ & domestic production & $P$ & price of domestic production \\
\hline$X A$ & Armington's composite good production & $P A$ & price of Armington's composite good \\
\hline$M$ & imports & $P M$ & price of imports \\
\hline$E$ & exports & $P E$ & price of exports \\
\hline$C P$ & household consumption & $P C P$ & price of consumption \\
\hline$C G$ & government consumption & $P C G$ & price of government consumption \\
\hline$I P$ & investment & $P I P$ & price of private investment \\
\hline$I G$ & public investment & $P I G$ & price of public investment \\
\hline$H A$ & Household income & $P L$ & wages \\
\hline$G O V$ & Government revenue & $P K$ & capital service price index \\
\hline$K S$ & capital stocks & $P F$ & farmland rents \\
\hline KO & capital demand (depreciation expense) & $r k$ & depreciation rate of capital stocks \\
\hline LO & labor demand & $\operatorname{taxl}$ & tax rate for labor input \\
\hline Fo & farmland demand & taxk & tax rate for capital input \\
\hline IOO & intermediate inputs & $\operatorname{taxy}$ & output tax rate \\
\hline TMO & Tariff revenue & taxm & tariff rate \\
\hline \multirow[t]{3}{*}{ CPSO } & private consumption by commodities & $L S 0^{*}$ & labor supply \\
\hline & and regions (disaggregation of CP0) & $\mathrm{FSO}^{*}$ & farmland supply \\
\hline & & $T F P^{*}$ & total factor productivity in rice sec. \\
\hline CGSO & $\begin{array}{l}\text { government consumption by commodities } \\
\text { and regions (disaggregation of CG0) }\end{array}$ & $S G^{*}$ & government savings \\
\hline IGSO & $\begin{array}{l}\text { public investment by commodities and } \\
\text { regions (disaggregation of IG0) }\end{array}$ & $S F^{*}$ & savings in foreign account \\
\hline IPSO & $\begin{array}{l}\text { private investment by commodities and } \\
\text { regions (disaggregation of IP0) }\end{array}$ & $T R F^{*}$ & regional transfer \\
\hline
\end{tabular}

(Note) Variables with "0" at the end show the initial level of each variable named ahead in the model description. Variables with "*” are exogenous variables. 


\section{Acknowledgements}

This study was supported by the research project "Economic Evaluation of Agricultural Mitigation and Adaptation Technologies for Climate Change" (Ministry of Agriculture, Forestry and Fishery), SOUSEI Program "Precise Impact Assessments on Climate Change" (Ministry of Education, Culture, Sports, Science, and Technology) and JSPS KAKENHI Grant Number (24330073). Climate data used here were provided by Dr. Motoki Nishimori (National Institute for Agro-Environmental Sciences). The authors sincerely express gratitude for their support.

\section{References}

Bann, K. (2007) Multi-regional Dynamic Computable General Equilibrium Model of Japanese Economies: Forward Looking Multi-regional Analysis. RIETI Discussion Paper Series, 07-J-043.

Calzadilla, A. et al. (2011) Water scarcity and the impact of improved irrigation management: a computable general equilibrium analysis. Agricultural Economics, 42, 305-323.

Egaitsu, N. (1985) ed. An Economic Analysis on Japanese Agriculture: Habit Formation, Technological Progress and Information, Taimeido press, Tokyo.

Furuya, J. \& Koyama, O. (2005) Impacts of Climatic Change on World Agricultural Product Markets: Estimation of Macro Yield Function. JARQ, 39, 121-134.

Iizumi, T. et al. (2009) Parameter estimation and uncertainty analysis of a large-scale crop model for paddy rice: Application of a Bayesian approach. Agricultural and Forest Meteorology, 149, 333-348.

K-1 model developers (2004) K-1 coupled model (MIROC) description. K-1 technical report 1. Hasumi H, Emori S. (eds) K-1 Technical Report 1, Center For Climate System Research,
Univ. of Tokyo, Kashiwa, Japan, 1-34.

Kunimitsu (2009) Macro Economic Effects on Preservation of Irrigation and Drainage Facilities: Application of Computable General Equilibrium Model. J. of Rural Econ. Special Issue 2009, 59-66.

Kunimitsu, Y. et al. (2013) Is long-term climate change beneficial or harmful for rice total factor productivity in Japan: Evidence from a panel data analysis. Paddy and Water Environment, DOI 10.1007/s10333-013-0368-0.

Lee, H. (2009) The impact of climate change on global food supply and demand, food prices, and land use. Paddy and Water Environment, 7, 321-331.

Masui, T. (2005) Policy evaluation under environmental constraints using a computable general equilibrium model. European Journal of Operational Research, 166, 843-855.

Nakicenovic, N. \& Swart, R. (2000) Special report on emissions scenarios: a special report of working group III of the intergovernmental panel on climate change. Cambridge University Press, Cambridge, 612.

Palatnik, R. R. \& Roson, R. (2012) Climate change and agriculture in computable general equilibrium models: alternative modeling strategies and data needs. Climate Change, 112, 1085-1100.

Rutherford, T. (1999) Applied General Equilibrium Modeling with MPSGE as a GAMS Subsystem: An Overview of the Modeling Framework and Syntax. Computational Economics, 14, 1-46.

Saito, K. (2002) Public Investment and the Economy-Wide Effects: An Evaluation of Agricultural Land Consolidation in Japan. Proceedings on International Conference of Policy Modeling, 2002.

Stern, N. (ed) (2006) The economies of climate change: the stern review. H. M. Treasury, UK.

Yokozawa, M. et al. (2009) Large scale Projection of Climate Change Impacts on Variability in Rice Yield in Japan. Globe Environment, 14, 199-206. 